\title{
INCLUSÃO ESCOLAR E EDUCAÇÃO ESPECIAL: INTERFACES NECESSÁRIAS PARA A FORMAÇÃO DOCENTE ${ }^{1}$
}

GLAT, Rosana; PLETSCH, Marcia Denise. Inclusão escolar de alunos com necessidades educacionais especiais. Rio de Janeiro: EdUERJ, 2011, 162p. (Pesquisa em Educação).

Giovani Ferreira BEZERRA² Doracina Aparecida de Castro ARAUJO ${ }^{3}$

O livro Inclusão Escolar de Alunos com Necessidades Especiais é resultado do primoroso encontro teórico-metodológico e institucional de duas pesquisadoras com reconhecido prestígio acadêmico no cenário da Educação Especial brasileira. Em cinco capítulos bem fundamentados, empírica e conceitualmente, Rosana Glat, da Universidade do Estado do Rio de Janeiro (UERJ), e Marcia Denise Pletsch, da Universidade Federal Rural do Rio de Janeiro (UFRRJ), revelam um lúcido posicionamento quanto à inclusão escolar de alunos com necessidades educacionais especiais em turmas regulares.

No primeiro capítulo, fazem uma rápida contextualização histórica para evidenciar a emergência da educação inclusiva como paradigma educacional. Em seguida, explicitam a conceituação de necessidades educacionais especiais, entendidas como as demandas resultantes da relação entre as características individuais do aluno e o contexto histórico-cultural onde está inserido. Ainda neste capítulo, descrevem brevemente as formas complementares de atendimento educacional especializado, a saber: ensino itinerante, bidocência, mediação de aprendizagem e salas de recurso, aproveitando a ocasião para criticar as atuais salas de recursos multifuncionais implantadas pelo Ministério da Educação (MEC), em que um professor deve atender alunos com diferentes condições cognitivas.

No segundo capítulo, as autoras discutem sobre aspectos estruturais e funcionais que perpassam o processo de inclusão escolar em três redes municipais da educação fluminense - Angra dos Reis, Niterói e Rio de Janeiro. A análise revela que, na prática, a política nacional de educação inclusiva tem sido desrespeitada, pois, nos municípios pesquisados, alunos com graves deficiências continuam sendo encaminhados exclusivamente para escolas ou classes especiais, além de passarem por avaliações descontextualizadas, muito próximas do modelo clínico

\footnotetext{
${ }^{1}$ A produção desta resenha contou com o financiamento da Capes, por meio de bolsa para pesquisa de mestrado no programa de Pós-Graduação da Universidade Estadual de Mato Grosso do Sul (UEMS), Unidade Universitária de Paranaíba e também é resultante dos estudos que temos procurado desenvolver na Linha de Pesquisa Educação Escolar Inclusiva, vinculada ao Grupo de Estudos e Pesquisas em Práxis Educacional (GEPPE).

${ }^{2}$ Mestrando em Educação pelo programa de Pós-Graduação da Universidade Estadual de Mato Grosso do Sul (UEMS), Unidade Universitária de Paranaíba, com bolsa da CAPES. gio_bezerra@hotmail.com

${ }^{3}$ Doutora em Educação pela Universidade Estadual de Campinas (UNICAMP). Docente e coordenadora do Programa de Pós-Graduação em Educação, nível de Mestrado, da UEMS/Paranaíba-MS. doracina@uems.com
} 
com fins de diagnóstico. Nota-se também a presença de alunos incluídos sem qualquer atendimento especializado, demonstrando-se que a escola inclusiva ainda não superou a seletividade, a precariedade de recursos humanos e materiais, num flagrante desencontro entre o real e o legal.

No terceiro capítulo, são apresentados dados de uma pesquisa etnográfica realizada em dezesseis classes de duas escolas da rede pública municipal do Rio de Janeiro. Pela abundância de depoimentos de professoras das escolas regulares, coordenadoras e observações retiradas do diário de campo das autoras, nota-se a predominância do empobrecimento curricular para os alunos com necessidades especiais, em vez de uma reorientação metodológica significativa, que lhes possibilitasse não só a propalada socialização, mas também o desenvolvimento acadêmico. Nesse contexto, o suporte da educação especial aos alunos e professores das classes comuns é visto como imprescindível para se promover à educação inclusiva de forma consequente.

Continuando essas reflexões, o quarto capítulo, sugere que o maior entrave à escola inclusiva ainda está na precariedade da formação inicial e continuada dos professores das salas comuns. Sem conhecimentos específicos sobre como ensinar alunos com diferenças evidentes na aprendizagem, eles acabam não acreditando nas possibilidades cognitivas dos educandos ou se frustrando com intervenções inadequadas. Como contrapartida, Glat e Pletsch apontam a pesquisa-ação como uma estratégia formativa a ser desenvolvida com os docentes, exemplificando tal proposta com dados de seus estudos.

No quinto capítulo, é traçado um panorama dos trabalhos realizados desde 2003 pelo grupo de pesquisas Inclusão e aprendizagem de alunos com necessidades especiais: práticas, pedagógicas, cultura escolar e aspectos psicossociais, vinculado à UERJ e associado à UFRRJ. Ao relatar brevemente os resultados desses trabalhos, as pesquisadoras confirmam o percurso teórico que adotam no livro, revelando sintonia temática e metodológica com os demais estudiosos do assunto, além de explicitarem problemas estruturais das escolas que têm limita a efetivação de uma práxis pedagógica inclusiva.

Em síntese, todo o livro é ricamente estruturado com base em dados coletados a partir de pesquisas de campo etnográficas e/ou de pesquisas-ação, constituindo-se, portanto, em uma referência imprescindível para educadores, gestores e pesquisadores que queiram compreender a educação especial na perspectiva inclusiva, sem falsos apelos idealistas, mas sim pela complexa interrelação entre políticas, práticas pedagógicas e cultura escolar, seja no Rio de Janeiro ou em qualquer outro estado do Brasil. Trata-se de uma leitura formativa do começo ao fim, enriquecida por um prefácio cuidadosamente redigido pela Prof ${ }^{a}$ Dr $^{\mathrm{a}}$ Eniceia Mendes, que antecipa ao leitor a relevância da obra e instiga o debate sobre os dilemas atuais da inclusão, desafiando-nos a rever nossos saberes e fazeres supostamente inclusivos. 